\title{
Commentary
}

\section{The UN Decade of Nutrition, the NOVA food classification and the trouble with ultra-processing}

\author{
Carlos Augusto Monteiro 1,2,*, Geoffrey Cannon ${ }^{2}$, Jean-Claude Moubarac ${ }^{2,3}$, \\ Renata Bertazzi Levy 2,4 , Maria Laura C Louzada ${ }^{2}$ and Patrícia Constante Jaime ${ }^{1,2}$ \\ 'Department of Nutrition, School of Public Health, University of São Paulo, Av. Dr Arnaldo 715, São \\ Paulo 01246-904, Brazil: ${ }^{2}$ Center for Epidemiological Research in Nutrition and Health, University of São Paulo, \\ São Paulo, Brazil: ${ }^{3}$ Département de Nutrition, Université de Montréal, Montréal, Canada: ${ }^{4}$ Department of Preventive \\ Medicine, School of Medicine, University of São Paulo, São Paulo, Brazil
}

Submitted 27 October 2016: Final revision received 18 January 2017: Accepted 23 January 2017: First published online 21 March 2017

\begin{abstract}
Given evident multiple threats to food systems and supplies, food security, human health and welfare, the living and physical world and the biosphere, the years 2016-2025 are now designated by the UN as the Decade of Nutrition, in support of the UN Sustainable Development Goals. For these initiatives to succeed, it is necessary to know which foods contribute to health and well-being, and which are unhealthy. The present commentary outlines the NOVA system of food classification based on the nature, extent and purpose of food processing. Evidence that NOVA effectively addresses the quality of diets and their impact on all forms of malnutrition, and also the sustainability of food systems, has now accumulated in a number of countries, as shown here. A singular feature of NOVA is its identification of ultra-processed food and drink products. These are not modified foods, but formulations mostly of cheap industrial sources of dietary energy and nutrients plus additives, using a series of processes (hence 'ultra-processed'). All together, they are energy-dense, high in unhealthy types of fat, refined starches, free sugars and salt, and poor sources of protein, dietary fibre and micronutrients. Ultra-processed products are made to be hyper-palatable and attractive, with long shelf-life, and able to be consumed anywhere, any time. Their formulation, presentation and marketing often promote overconsumption. Studies based on NOVA show that ultra-processed products now dominate the food supplies of various high-income countries and are increasingly pervasive in lowermiddle- and upper-middle-income countries. The evidence so far shows that displacement of minimally processed foods and freshly prepared dishes and meals by ultra-processed products is associated with unhealthy dietary nutrient profiles and several diet-related non-communicable diseases. Ultra-processed products are also troublesome from social, cultural, economic, political and environmental points of view. We conclude that the ever-increasing production and consumption of these products is a world crisis, to be confronted, checked and reversed as part of the work of the UN Sustainable Development Goals and its Decade of Nutrition.
\end{abstract}

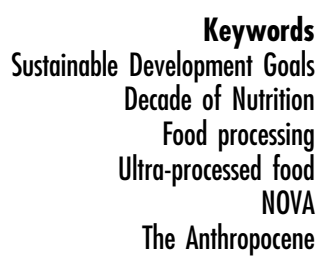

On 1 April 2016 the UN General Assembly proclaimed the Decade of Nutrition, to run from 2016 to 2025 as part of the UN Sustainable Development Goals initiative ${ }^{(1)}$. It will be guided by the FAO, the WHO and other UN agencies, with support requested from civil society and the private sector. All concerned repeatedly emphasize that this work is crucial, because of the evident multiple worsening threats to food systems and supplies, and thus to food security, human health and welfare, the living and physical world and the biosphere. At the General Assembly 
meeting, FAO Director-General José Graziano da Silva stated: 'This Resolution puts nutrition at the heart of sustainable development'.

\section{Identification of ultra-processed food and drink products}

In support of the UN initiatives, in September 2016 the Global Panel on Agriculture and Food Systems for Nutrition, an independent expert group one of whose members is the FAO director-general, published its 'Foresight' report on Food Systems and Diets: Facing the Challenges of the 21 st Century (2). This includes important recommendations and advice for leaders at the most senior levels in countries and international organizations'. Its findings 'constitute a stark warning for all countries ... the situation is set to worsen dramatically over the next 20 years as powerful drivers of change such as population growth, climate change and urbanization converge on food systems'. As an example:

\section{'If the direction of current policies remains the same, then estimates suggest that by 2030, the number of overweight and obese people will have increased from 1.33 billion in 2005 to 3.28 billion, around one third of the projected global population. This is a major concern as no country to date has success- fully reversed growth in obesity once it has been allowed to develop.'}

In this context, specific reference is made to production and consumption of ultra-processed food and drink products as a reason for the rise in obesity:

'In 2000, sales of ultra-processed foods and beverages in the upper-middle-income countries were one third of those in the high-income countries. Fifteen years later, they were more than half.'

The term 'ultra-processed' was explained and given a context:

"The term "ultra-processed" was coined to refer to industrial formulations manufactured from substances derived from foods or synthesized from other organic sources. They typically contain little or no whole foods, are ready-to-consume or heat up, and are fatty, salty or sugary and depleted in dietary fibre, protein, various micronutrients and other bioactive compounds. Examples include: sweet, fatty or salty packaged snack products, ice cream, sugar-sweetened beverages, chocolates, confectionery, French fries, burgers and hot dogs, and poultry and fish nuggets.'

As also stated in a 2015 report published by the Pan American Health Organization (PAHO) of the $\mathrm{WHO}^{(3)}$ :

'The most striking change in food systems of highincome countries, and now of low- and middleincome countries, is displacement of dietary patterns based on meals and dishes prepared from unprocessed or minimally processed foods by those that are increasingly based on ultra-processed food and drink products. The result is diets with excessive energy density, high in free sugars and unbealthy fats and salt, and low in dietary fiber that increase the risk of obesity and other diet-related non-communicable diseases. The proportion of ultra-processed products in food supplies can be seen as a measure of overall population diet quality.'

The September 2016 'Foresight' report, which ends with an annex listing all types of ultra-processed food products, goes on to state ${ }^{(2)}$ :

'Sales of ultra-processed food and sugar-sweetened beverages are growing. This growth is almost exclusively found in lower-middle income and upper-middle-income countries ... Sales of ultraprocessed foods in East and South East Asia are expected to approach those of high-income countries by 2035 .'

The concept of ultra-processing, developed by a team at the University of São Paulo of which we are members, was first proposed in a Public Health Nutrition commentary in $2009^{(4)}$. It was created as part of the thesis that the nature, extent and purpose of food processing explain what is now the relationship between food, nutrition, health and disease. This thesis is now acknowledged in reports, statements and commentaries from the $\mathrm{FAO}^{(5,6)}$ and $\mathrm{PAHO}^{(3,7)}$, and in leading scientific journals ${ }^{(8,9)}$. It has been used in an official national set of food-based dietary guidelines $^{(10,11)}$ and by many investigators in several countries (see later). It was initially summarized as follows $^{(4)}$ :

'The most important factor now, when considering food, nutrition and public bealth, is not nutrients, and is not foods, so much as what is done to foodstuffs and the nutrients originally contained in them, before they are purchased and consumed. That is to say, the issue is food processing - or, to be more precise, the nature, extent and purpose of processing, and what happens to food and to us as a result of processing.'

The present commentary has five main sections. First, we give reasons why proper understanding of the relationship between diet and public health now needs to emphasize food processing. Second, we specify the need to make precise definitions of food processing and to distinguish between different types of processing. Third, we present NOVA, the food classification based on the nature, extent and purpose of food processing that places foodstuffs in four groups, one of which is specified as ultra-processed food and drink products. Fourth, we summarize the use of NOVA in a number of countries to describe and monitor 
population dietary patterns and to assess the impact of ultra-processed products on the quality of diets and health outcomes. Fifth, we summarize some health, social, economic, political and environmental consequences of replacing minimally processed foods and freshly prepared meals by ultra-processed products. Then finally, we propose that the rapidly increasing production and consumption of ultra-processed food and drink products, which is contributing to climate disruption and also to pollution, degradation and depletion of air, land, water and sources of energy, is in itself now a world crisis to be confronted, checked and reversed as part of the UN Sustainable Development Goals and its Decade of Nutrition.

\section{Reasons to emphasize food processing}

Special attention to food processing is now crucial in order to understand the connection between diet and public health. Here are five reasons that justify this statement. They explain why the NOVA classification has been developed and why it is necessary to identity the sources of ultra-processed products.

One. Conventional food classifications no longer work well. They usually group foods and foodstuffs in terms of their botanical origin or animal species and according to nutrients they contain. In this way they often group together foods that have different effects on health and disease. So 'cereals and cereal products' often group whole grains together with sugared 'breakfast cereals' and cookies (biscuits), and 'meat and meat products' often group fresh chicken together with 'nuggets'. This sidelining of food processing has serious consquences, as shown below.

Two. Evidence on the relationship between food processing and health outcomes has been increasing steadily. An obvious example is industrial trans-fats, produced by the partial hydrogenation process in the manufacture of a vast number of fatty branded packaged products, including margarines, biscuits and other 'long-life' baked goods. Trans-fats are now known to be a cause of $\mathrm{CVD}^{(12)}$. Reports issued by UN agencies and other authoritative organizations $^{(13,14)}$ list some processed foods and drinks as certainly or probably implicated in obesity and chronic diseases. These include energy-dense food products, fast foods, soft drinks, sugary drinks, refined starchy foods, processed meat and salt-preserved foods. But such reports apparently do not see any pattern, and stop short of examining processing as such. Both the US 2010 and the 2015-2020 Dietary Guidelines for Americans reports ${ }^{(15,16)}$ advise less consumption of common ingredients of processed foods such as sodium, added sugars, trans-fats, refined grains and processed meats. Yet these reports also do not examine processing as such, and the term 'processing' is not even included in their glossaries of terms. Also, concern about food additives is usually limited and confined to issues of contamination; much less attention is given to the use of cosmetic food additives (notably, flavours and colours) that are used in order to make combinations of cheap processed oils, refined sugars and starches palatable and attractive.

Three. Food systems and supplies are changing globally and are determining changes in food purchase and consumption. Specialist food retailers are being rapidly displaced by supermarkets whose central aisles are dominated by branded packaged products. Home cooking has decreased in favour of snacking on processed products, consumption of pre-prepared dishes, and the very rapid rise of franchised fast-food caterers selling processed meat products, French fries and sugared soft drinks. Branded products such as fatty, sugary or salty snack foods and sugared soft drinks are available in all sorts of retail outlets, often round the $\operatorname{clock}^{(2,6,17)}$.

Four. All these phenomena are being driven by transnational corporations. These corporations are identified in a 2012 PLoS Medicine series, and in 2014 by Margaret Chan, Director-General of the WHO, as 'Big Food'(18,19). Since the 1980s they have taken advantage of the freedom to make foreign direct investments, an engine of economic growth, which, as reported by the Organisation for Economic Co-operation and Development, have risen from \$US 61 million in 1985 to \$US 1068000 million in 2000 and to \$US 1730000 million in $2015^{(20,21)}$. This has dramatically changed food supplies in middle- and lowincome countries, as shown elsewhere ${ }^{(22,23)}$. The annual turnovers of a number of corporations exceed the gross national product of mid-range countries and, unlike many national governments, they can divert or invest billions of dollars in new technologies and markets ${ }^{(24)}$. As stated in a 2000 report by the Global Policy Forum ${ }^{(25)}$ :

\section{'Although TNCs [transnational corporations] are collectively the world's most powerful economic force, no intergovernmental organisation is charged with governing their behaviour. The unwillingness or inability of governments to control TNCS in a period of deregulated global trade and investment does not bode well [is not good] for people's health or the environment.'}

Five, and related. It is now becoming increasingly well known that transnational food corporations have colossal resources to manufacture, market, promote and lobby for their packaged branded products. Their impact is most evident in the middle- and low-income countries they have penetrated since the 1980s, where they often plan 'double-digit' growth, meaning $10 \%$ or more increase in annual sales ${ }^{(24)}$. As pointed out in the September 2016 'Foresight' report $^{(2)}$ :

'Food and beverage companies spend large amounts on advertising, accounting (including alcohol retail) for $17 \%$ of global media spending in 2012. Coca Cola and Nestle, which were among the top ten 
largest global advertisers in 2014, together spent US $\$ 6 \cdot 21$ billion - equivalent in size to almost twothirds of the entire UK overseas aid budget.

A recent review of food marketing practices concludes that food promotion in high-income countries has been geared towards increased access to cheaper, bigger and tastier calorie-dense food. Much consumer influencing is conducted "below the radar" using less obvious methods than advertising, such as brand association, sensory complexity, the size and shape of portions, packages and serving containers. These practices are also following similar patterns in low-and middle-income countries. There is convincing evidence that advertising influences food choice among children.'

Taken all together, these and other factors, including the impact of ultra-processed food and drink products on social life, culture, employment and the environment, of which more below, show that in this 21st century it is necessary to pay special attention to food processing and to ultra-processed products (see Box 1).

\section{Food processing as such is not the issue}

So, what does 'processing' mean? Organizations that represent the interests of food and drink corporations ${ }^{(26,27)}$ or professional organizations ${ }^{(28-30)}$ that are supported by food product manufacturers ${ }^{(31)}$ have published reports, brochures or papers between 2010 and 2014 on food processing. These use very broad characterizations, such as 'food processing is any deliberate change made in a food from the time of origin to the time of consumption'(26), or 'a variety of operations by which raw foodstuffs are made suitable for consumption, cooking, or storage $^{,(27)}$, or else 'food processing is the alteration of foods from the state in which they are harvested or raised to better preserve them and feed consumers ${ }^{,(30)}$.

Additives are explained with statements such as ${ }^{(27)}$ :

'Food additives are added for a particular purpose whether it is to ensure food safety, to add nutritional value or to improve food quality. They play an important role in preserving the freshness, safety, taste, appearance and texture of foods. For example, antioxidants prevent fats and oils from becoming rancid whereas emulsifiers stop peanut butter from separating into solid and liquid fractions. Food additives keep bread free of mould for longer and allow fruit jams to "gel" so they can be spread onto bread.'

It is also true in a broad sense that ${ }^{(27)}$ :

'We all process foods everyday when preparing a meal for ourselves or our family and virtually all

Box 1 The food industry is essential

It is sometimes thought that concerns about food processing amount to some sort of attack on the food industry in general. Indeed, public statements made about food, nutrition and health often refer critically to 'the food industry' without giving any clear idea of what is being referred to.

This practice is unhelpful. The food industry as a whole is obviously essential for the welfare and survival of the human race, for the sustenance of civilizations, and now for the reliable supply of food to rapidly growing urban populations. Food production, preservation, manufacture, distribution and sale create safe, secure and convenient food supplies for all populations and communities with adequate and stable disposable incomes, all over the world.

The food industry includes farmers and other food and drink producers, manufacturers, distributors, retailers and caterers, and associated industries, of all sizes, and their unions and trade organizations ${ }^{(9)}$. These and other workers, cooperatives, tradesmen, shopkeepers, entrepreneurs, industrialists, and their representatives, are all together the true food system 'private sector'. It is practically meaningless to characterize 'the food industry', a very broad term, as if any critical judgement could be made of industry as a whole.

Any meaningful critical judgement on the present role played by the food industry within food systems needs to isolate the transnational and other very large corporations and companies whose profits depend on food and drink products which, consumed at levels now usual in many countries, and projected to be so in most countries, are a major cause of concern for global public health. Specifically, the critical focus needs to be on the lightly regulated transnational manufacturing and catering corporations and their trade, representative and allied organizations that dominate the market for ultra-processed food products. These corporations and organizations are often identified and treated as if they are 'the food industry' or even 'the private sector'. But they do not and cannot represent the interests of the food industry as a whole.

Singling out transnational corporations does not mean that they are solely responsible. They have been enabled to grow very fast and to become very powerful because of political and economic trade policies agreed at global level that have given them extraordinary freedom to do what they want within existing laws. 
foods undergo some form of processing before they are ready to eat ... Processing spans the whole food chain from harvesting on the farm to different forms of culinary preparation in the home.'

Practically all food is processed in some sense and in some way, including by 'other procedures' not mentioned above such as hydrogenation, hydrolysation and extrusion. Thus the term 'processing' (like the term 'industry') is very general and therefore not helpful. It is a mistake to make any judgement of food supplies or foods simply because they are 'processed'. Further, attempts to distinguish between different types of processing by using undefined terms such as 'highly' or 'heavily' processed, or 'fast', 'convenience', 'snack' or 'junk' food, are also unhelpful.

Verdicts on food processing as such have little or no meaning. Food scientists and technologists and food manufacturers rightly emphasize the benefits of originally ancient and also relatively novel processes such as drying, non-alcoholic fermentation, chilling and freezing, pasteurization and vacuum-packing. But on the other hand just to take two examples - evidence on the harm done by partial hydrogenation is now conclusive, and on sugaring (notably with soft drinks or 'soda') is very strong ${ }^{(12-14)}$.

It is possible to make sense of food processing and its effects on human health only when analysis and assessment are discriminating and precise, with terms defined and with types, uses and effects of processing identified and distinguished. Definitions need to be meaningful, detailed and objective, which is to say specific, coherent, clear, comprehensive and workable. This is part of the purpose of the NOVA food classification ${ }^{(4,5,11,32-35)}$.

\section{The NOVA classification}

NOVA (which is not an acronym) groups foods according to the nature, extent and purpose of the industrial processing they undergo. Food processing as identified by NOVA involves physical, biological and chemical processes used after foods are separated from nature, and before being consumed or prepared as dishes and meals.

Foods may be consumed by themselves (such as fruits, nuts, milk); or as a main item or accompanying items of dishes and meals (such as grains, flours, vegetables, meat, eggs); or as food products used in making these dishes and meals (such as oils, butter, sugar, salt). Or, they may be food products ready to consume or heat (such as bread, cheese, ham; packaged snacks, soft drinks, pre-prepared frozen dishes). NOVA classifies all foods and food products into four groups. See the Appendix for detailed lists of foods and food products in each of the four groups.

\section{Group 1. Unprocessed or minimally processed foods} Unprocessed (or natural) foods are edible parts of plants (seeds, fruits, leaves, stems, roots) or of animals (muscle, offal, eggs, milk), and also fungi, algae and water, after separation from nature. Minimally processed foods are natural foods altered by processes that include removal of inedible or unwanted parts, and drying, crushing, grinding, fractioning, filtering, roasting, boiling, non-alcoholic fermentation, pasteurization, refrigeration, chilling, freezing, placing in containers and vacuum-packaging. These processes are designed to preserve natural foods, to make them suitable for storage, or to make them safe or edible or more pleasant to consume. Many unprocessed or minimally processed foods are prepared and cooked at home or in restaurant kitchens in combination with processed culinary ingredients as dishes or meals.

\section{Group 2. Processed culinary ingredients}

Processed culinary ingredients, such as oils, butter, sugar and salt, are substances derived from Group 1 foods or from nature by processes that include pressing, refining, grinding, milling and drying. The purpose of such processes is to make durable products that are suitable for use in home and restaurant kitchens to prepare, season and cook Group 1 foods and to make with them varied and enjoyable hand-made dishes and meals, such as stews, soups and broths, salads, breads, preserves, drinks and desserts. They are not meant to be consumed by themselves, and are normally used in combination with Group 1 foods to make freshly prepared drinks, dishes and meals.

\section{Group 3. Processed foods}

Processed foods, such as bottled vegetables, canned fish, fruits in syrup, cheeses and freshly made breads, are made essentially by adding salt, oil, sugar or other substances from Group 2 to Group 1 foods. Processes include various preservation or cooking methods, and, in the case of breads and cheese, non-alcoholic fermentation. Most processed foods have two or three ingredients, and are recognizable as modified versions of Group 1 foods. They are edible by themselves or, more usually, in combination with other foods. The purpose of processing here is to increase the durability of Group 1 foods, or to modify or enhance their sensory qualities.

\section{Group 4. Ultra-processed foods}

Ultra-processed foods, such as soft drinks, sweet or savoury packaged snacks, reconstituted meat products and pre-prepared frozen dishes, are not modified foods but formulations made mostly or entirely from substances derived from foods and additives, with little if any intact Group 1 food.

Ingredients of these formulations usually include those also used in processed foods, such as sugars, oils, fats or salt. But ultra-processed products also include other sources of energy and nutrients not normally used in culinary preparations. Some of these are directly extracted from foods, such as casein, lactose, whey and gluten. Many are derived from further processing of food constituents, such as hydrogenated or interesterified oils, 
hydrolysed proteins, soya protein isolate, maltodextrin, invert sugar and high-fructose corn syrup.

Additives in ultra-processed foods include some also used in processed foods, such as preservatives, antioxidants and stabilizers. Classes of additives found only in ultra-processed products include those used to imitate or enhance the sensory qualities of foods or to disguise unpalatable aspects of the final product. These additives include dyes and other colours, colour stabilizers; flavours, flavour enhancers, non-sugar sweeteners; and processing aids such as carbonating, firming, bulking and anti-bulking, de-foaming, anti-caking and glazing agents, emulsifiers, sequestrants and humectants.

A multitude of sequences of processes is used to combine the usually many ingredients and to create the final product (hence 'ultra-processed'). The processes include several with no domestic equivalents, such as hydrogenation and hydrolysation, extrusion and moulding, and pre-processing for frying.

The overall purpose of ultra-processing is to create branded, convenient (durable, ready to consume), attractive (hyper-palatable) and highly profitable (low-cost ingredients) food products designed to displace all other food groups. Ultra-processed food products are usually packaged attractively and marketed intensively.

\section{NOVA in use}

The NOVA classification has now been applied worldwide. Uses so far include description of population dietary patterns, assessments of changes over time in the dietary share of ultra-processed products, and analyses of the association of this share with the nutrient profile of diets and with health outcomes.

In Brazil, NOVA has been used to assess: the socio-economic and demographic distribution of dietary patterns ${ }^{(36,37)}$; time changes in dietary patterns ${ }^{(36,38)}$; the impact of the dietary share of ultra-processed products on the dietary content of macronutrients ${ }^{(39-41)}$ and micronutrients ${ }^{(42)}$; and the association of consumption of ultra-processed products with obesity ${ }^{(43,44)}$, metabolic syndrome $^{(45)}$ and dyslipidaemias ${ }^{(46)}$. NOVA has also been used in Brazil to study the relationship between household food purchase patterns and relative prices of ultraprocessed and all other food items ${ }^{(47)}$, as well as the influence of the food environment ${ }^{(48-50)}$ and of food advertising $^{(51)}$ on the consumption of ultra-processed products; and to evaluate the impact of a nutrition education intervention ${ }^{(52)}$.

In the USA, NOVA has been used to describe population dietary patterns and to assess the impact of ultraprocessed products on the overall consumption of added sugar $^{(53)}$, on the dietary content of other critical macronutrients and micronutrients ${ }^{(54)}$, and on urinary levels of phyto-oestrogens ${ }^{(55)}$. With some adaptation, it has been used also to evaluate the nutritional quality of packaged foods purchased by US households and to study differences in purchase according to race/ethnicity ${ }^{(56,57)}$. In Canada, it has been used to assess secular trends in national dietary patterns ${ }^{(58)}$ and the impact of ultraprocessed products on indicators of nutrient profile of $\operatorname{diets}^{(59,60)}$. In the UK, NOVA has been used to describe population dietary patterns and to study the relationship between household food purchase patterns and relative prices of ultra-processed and all other food items ${ }^{(47)}$, and to estimate the potential for reduction of CVD by reducing consumption of ultra-processed products ${ }^{(61)}$. In Australia, it has been used to assess dietary sodium intake and food sources of sodium ${ }^{(62)}$, to study national time trends in aspects of food practices implicated in diet-related health risks $^{(63)}$, and to build a tool to measure healthy and sustainable dietary behaviours ${ }^{(64)}$.

In Chile, NOVA has been used to describe population dietary patterns and to assess the impact of the consumption of ultra-processed products on the nutritional quality of diets $^{(65,66)}$. It has been used in Mexico to describe population dietary patterns and determinants of consumption of ultra-processed food products ${ }^{(67)}$. In Norway, it has been used to assess the participation of ultra-processed foods in national food sales ${ }^{(68)}$; in New Zealand, to describe the nutrient profile of supermarket foods ${ }^{(69)}$; and in Sweden to study time trends in consumption of ultra-processed products and in adult obesity ${ }^{(70)}$. In Spain, the association between the consumption of ultra-processed foods and the 9-year incidence of obesity and hypertension was tested in a cohort of middle-aged adults ${ }^{(71,72)}$.

Studies on time trends in sales of ultra-processed products have covered seventy-nine middle- and high-income countries $^{(73)}$ and fourteen countries in $\mathrm{Asia}^{(74)}$. A paper published in The Lancet in $2013^{(9)}$ compared strategies used by the manufacturers of tobacco, alcohol and ultraprocessed products, with implications for prevention and control of non-communicable diseases. A PAHO report described socio-economic determinants of sales of selected ultra-processed products in fifteen Latin American countries and analysed the association between annual changes in sales of these products and annual changes in population mean $\mathrm{BMI}^{(3)}$. A WHO report has used NOVA to assess and compare the impact of the dietary share of ultra-processed products on the excessive overall intake of free sugars in the USA, Canada, Brazil and Colombia ${ }^{(75)}$.

Altogether, studies based on NOVA show exponential growth in consumption of ultra-processed products and confirm that they displace unprocessed or minimally processed foods and freshly prepared dishes and meals made from these foods together with processed culinary ingredients. For example, between 1998 and 2012, per head sales of sweet or savoury snacks and soft drinks increased by $50 \%$ in upper-middle-income countries and by 100 and $300 \%$, respectively, in lower-middle-income countries ${ }^{(73)}$. In Brazilian urban households, ultra-processed products 
represented $18.7 \%$ of total energy of food baskets in 1988 , increasing by $50 \%$ to $29.6 \%$ in 2009 , while minimally processed foods declined from 44.0 to $38.9 \%$ and processed culinary ingredients from 35.7 to $28.9 \%{ }^{(38)}$.

Studies based on NOVA also show that the consumption of ultra-processed products increases the overall energy density of diets and their content of saturated and trans-fats and free sugars, and decreases dietary fibre, phyto-oestrogens, magnesium, potassium, vitamin A, iron and zinc, among other key micronutrients. For instance, the average content of added sugars in the US diet is $19.5 \%$ among the highest consumers of ultra-processed products (upper quintile) and $7.5 \%$ among the lowest consumers (lower quintile) ${ }^{(53)}$. In the Brazilian diet, the content of vitamin A, iron and zinc among the lowest consumers of ultra-processed products exceeds by 5, 15 and $25 \%$, respectively, the same content among the highest consumers ${ }^{(42)}$.

Ecological studies and cross-sectional and cohort studies have documented a direct association between ultra-processed products and obesity ${ }^{(3,43,44,70,71)}$, hypertension $^{(72)}$, metabolic syndrome ${ }^{(45)}$ and dyslipidaemias ${ }^{(46)}$.

NOVA has also been used to orient the nutrient profile model developed by the PAHO for the region of the Americas $^{(7)}$. The dietary share of ultra-processed products has been recommended by a leading international organization as a way to monitor the overall quality of national $\operatorname{diets}^{(76)}$.

The NOVA four food groups are also the basis for the four main recommendations of the current official national Brazilian dietary guidelines ${ }^{(10)}$, recognized by the $\mathrm{FAO}^{(6)}$ as the first food-based dietary guidelines that take social, cultural, economic and other aspects of sustainability into account. The main recommendations of the national dietary guidelines of Uruguay, published in December 2016, are also based on the NOVA four food groups ${ }^{(77)}$.

The main recommendations of the Brazilian guidelines are:

1. Make natural or minimally processed foods, in great variety, mainly of plant origin, and preferably produced with agro-ecological methods, the basis of your diet.

2. Use oils, fats, salt and sugar in small amounts for seasoning and cooking foods and to create culinary preparations.

3. Limit the use of processed foods, consuming them in small amounts as ingredients in culinary preparations or as part of meals based on natural or minimally processed foods.

4. Avoid ultra-processed products.

\section{The trouble with ultra-processing}

As stated, ultra-processed products are not modified foods, recognizable as such, but formulations of industrial sources of dietary energy and nutrients, particularly unhealthy types of fat, starches, free sugars and salt, plus additives including those designed to intensify sensory impact. They typically contain little or even no intact food.

The ingredients of ultra-processed products make them fatty, sugary or salty, often high in saturated fats or transfats, and depleted in dietary fibre and various micronutrients and other bioactive compounds. This is why, in several countries, as shown above, higher consumption of these products is associated with unhealthy dietary nutrient profiles and several diet-related non-communicable diseases.

When solid, because of their main ingredients and the lack of dietary fibre and water, the energy density of ultraprocessed products ranges from fairly high (about 940$1150 \mathrm{~kJ}(225-275 \mathrm{kcal})$ per $100 \mathrm{~g}$ for baked products) to high (about 1460-1675 kJ (350-400 kcal) per $100 \mathrm{~g}$ for 'energy' bars) or very high (1675-2090 kJ (400-500 kcal) per $100 \mathrm{~g}$ for most biscuits and for chips (crisps)) ${ }^{(10)}$. When formulated as drinks, ultra-processed products are often sugared, and are usually depleted in or devoid of nutrients. These attributes make most ultra-processed products prone to cause inadvertent overconsumption of dietary energy, and thus overweight and obesity ${ }^{(14,78)}$.

They also typically have high glycaemic loads ${ }^{(79)}$. This makes them liable to disturb and even derange endogenous processes in the nervous system that signal satiety and control appetite, and thus increase the risk of obesity and diabetes ${ }^{(13)}$.

Ultra-processed products are often formulated to be habit-forming, and are sometimes even quasi-addictive, which makes it hard to make healthy choices and to avoid overconsumption $^{(80,81)}$.

Many ultra-processed products create a false impression of being healthy by, for example, the addition of dietary fibre and some micronutrients and the replacement of sugar by artificial sweeteners, or the reduction of sodium, enabling manufacturers to make health claims despite the product remaining unhealthy ${ }^{(82,83)}$. Vast sums of money are spent by the biggest corporations on advertising and promotion of regular or reformulated products, including cross-advertising between brands, to make them attractive, exciting and even glamorous, especially to children and young people ${ }^{(84-86)}$. All these practices impede ability to make healthy choices.

Ultra-processed products now dominate the food supplies of various high-income countries. For instance, they made up $57.9 \%$ of the US food supply in 2009-2010 and $47.7 \%$ of the total dietary energy intake in Canada in $2004^{(60)}$. In middle-income countries, figures are lower, for instance $29.8 \%$ in Mexico ${ }^{(67)}, 28.6 \%$ in Chile ${ }^{(66)}$ and $21.5 \%$ in Brazil $^{(39)}$; but, as shown by sales data in Latin American countries $^{(3)}$, they are rising rapidly. Estimates of the contribution of ultra-processed products to the total dietary energy intake in low-income countries are not yet available, but the highest proportional increase in sales of sweet and savoury snacks and sugary soft drinks is seen in lower-middle-income countries ${ }^{(73)}$. 
Thus, ultra-processed products have troublesome effects on global nutrition and health. The evidence so far indicates that the displacement of unprocessed or minimally processed foods and freshly prepared dishes and meals by ultra-processed food and drink products is driving the high and increasing global burden of obesity and other diet-related chronic non-communicable diseases $^{(87)}$. The evidence also indicates that this change in dietary patterns can worsen the still relevant burden of micronutrient deficiencies in low- and middle-income countries ${ }^{(87)}$, notwithstanding the fortification of some ultra-processed products with some micronutrients.

Ultra-processed products and their makers are also causing social, cultural, economic, political, environmental and other problems. Much of what follows is obvious or common sense, and is much discussed in the literature. Some invites further research, which should not delay action to slow, stop and reverse the increases in production and consumption of ultra-processed products.

Social life in and out of the home is weakened by ultraprocessed products. Because they are convenient, being formulated as ready-to-consume snacks and drinks and ready-to-heat items, they displace dishes and meals made at home. The shared experiences of acquiring, preparing, cooking and enjoying food together, part of our evolution as humans ${ }^{(88,89)}$, with all the knowledge this brings of the nature, meaning and value of food, become increasingly lost. Meal tables and all that goes with them are used less often, or even not at all. The kitchen becomes less used and the dining room, a special place for people who live in the same place to come together and share in one another's lives, may disappear. Instead, people at home get into the habit of eating alone, at different times, inattentively, often when doing something else. Children and young people eat while using their computer or playing video games. Out of the house, ultra-processed products are consumed anywhere, any time, while working, walking or driving, or when using cell phones. These are generally isolated situations, concealed by advertisements and other marketing suggesting that ultra-processed products enhance social interaction ${ }^{(11,90,91)}$.

Culture, national and local, is also harmed by ultraprocessed products. Transnational ultra-processed food and drink manufacturers, distributors and caterers are increasingly oligopolistic ${ }^{(17,18,22)}$, and work in concert, as is evident from joint trade organizations set up to defend their shared interests ${ }^{(24)}$. Supported by international free trade agreements ${ }^{(92)}$, they displace authentic established varied food systems and cultures, and generate uniform consumer habits. Their strategy in effect is to teach the world to snack ${ }^{(93)}$. Everywhere, food customs that are part of the identity of countries and regions, and food cultures based on shared meals, are being undermined by ultraprocessed products, with their branding, promotion, packaging and labelling. The contents of any type of product - the soft drinks and burgers and many other ultra-processed products made by giant corporations - are much the same everywhere. The impression of variety is given by marketing campaigns with vast sums spent on them worldwide using multimedia, social media, the Internet and television, as well as all sorts of printed advertisements, which further invalidate what have been established dietary patterns, culinary knowledge and skills, and social cultures. This has an alienating effect on children and young people, who get the impression that the culture and nature of their own country and location, ethnicity and tradition are boring ${ }^{(11,94,95)}$.

Production and consumption of ultra-processed products also have troublesome economic consequences. Transnational and other big corporations using cheap ingredients for their products operate economies of scale and have huge reserves of money for investment and development. They may take over national and local businesses, including the makers, distributors and sellers of minimally processed foods ${ }^{(24,25)}$. In order to join in the market and to compete, national and regional manufacturers increasingly produce their own variations of ultra-processed products. Demand for cheap oils, sugar, starches and other common ingredients of ultra-processed products creates crop monocultures in many countries in order to produce raw materials usually for export and not foods for direct human consumption. Judgements vary on the economic effects. Some national and local businesses and family farmers adapt and flourish, but livelihoods especially of the most impoverished vulnerable and impoverished communities can be made even more insecure $^{(96-98)}$. In high- and middle-income countries, the price of most ultra-processed food products has decreased relative to that of most minimally processed foods ${ }^{(99)}$. But varied freshly prepared meals made from minimally processed foods with processed culinary ingredients can readily be made to be cheaper than ultra-processed products $^{(47,100-102)}$. Ultra-processed products also carry another cost: obesity and related chronic diseases such as diabetes are debilitating and impede ability to work, and their treatment, for those without health insurance or access to publicly funded health services, can mean financial catastrophe ${ }^{(96,103)}$.

There are also political consequences. Ultra-processed products have made the fortunes of the transnational food and drink corporations, of which, as mentioned, the largest have annual turnovers the size of middle-ranked national economies ${ }^{(24,25)}$. The deregulation that has enabled transnational corporations to grow exponentially, their ability to move into the countries that give them most scope and their freedom to act as they choose within the law, all give them more power and elected national governments less ability to act in the public interest ${ }^{(9,19,24,25)}$. Thus, it becomes difficult for governments, should they wish to do so, to enact fiscal and other statutory policies designed to make unprocessed and minimally processed foods more available and cheaper, and ultra-processed 
products less available and relatively or absolutely more expensive. WHO Director-General Margaret Chan has explained $^{(19)}$ :

'Efforts to prevent noncommunicable diseases go against the business interests of powerful economic operators.... It is not just Big Tobacco anymore. Public health must also contend with Big Food, Big Soda, and Big Alcohol. All of these industries fear regulation, and protect themselves by using the same tactics. Research has documented these tactics well. They include front groups, lobbies, promises of selfregulation, lawsuits, and industry funded research that confuses the evidence and keeps the public in doubt. Tactics also include gifts, grants, and contributions to worthy causes that cast these industries as respectable corporate citizens in the eyes of politicians and the public. They include arguments that place the responsibility for harm to bealth on individuals, and portray government actions as interference in personal liberties and free choice.

This is formidable opposition. Market power readily translates into political power. Few governments prioritize health over big business. As we learned from experience with the tobacco industry, a powerful corporation can sell the public just about anything. Let me remind you. Not one single country has managed to turn around its obesity epidemic in all age groups. This is not a failure of individual will-power. This is a failure of political will to take on big business.'

Production and consumption of ultra-processed products are also damaging the environment. For example in the USA, food packaging is about half of total packaging by weight and accounts for almost two-thirds of total packaging waste by volume ${ }^{(104)}$. Bottles, containers, wrappings and other packaging of ultra-processed products create colossal amounts of garbage, some not biogradable, thrown away in the street and countryside, washed out of sewers, and disposed of in landfill sites. The manufacture and distribution of ultra-processed products and their ingredients often involve long international transport routes and therefore excessive use of nonrenewable energy, which contributes to climate disruption $^{(105)}$. Intensive breeding of animals for human food is especially prodigal in its use of energy. Cattle bred for the burger trade require animal feed produced by monocultures such as of soyabeans and corn, and many other inputs including antibiotics, and in countries such as Brazil involve the destruction of great tracts of rainforest and savannah $^{(106,107)}$. All this, in common with other forms of industrial agriculture, contributes to climate disruption, causes pollution, loss of biodiversity, and depletion, degradation and losses of water, soil, energy and other non-renewable natural resources.

\section{Living in the Decade of Nutrition}

The Anthropocene, generally agreed as beginning in the 1950s, is the epoch in which human activities are disturbing natural planetary balance to an extent that may well become irreversible. Concerted public policies and actions are needed very urgently, to make life on Earth sustainable ${ }^{(108,109)}$.

Human activities that are thwarting sustainability include those leading to climate disruption; precipitate urbanization; the pollution, degradation and depletion of air, land, water and sources of energy; gross abuses and waste caused by mass production of animals; and food and nutrition insecurity ${ }^{(110)}$.

We propose that the ever-increasing production and consumption of ultra-processed food and drink products should be identified as one of the human activities leading to the crises listed above. We also propose that the impact of ultra-processed products on human health is itself a world crisis, to be confronted, checked and reversed as part of the UN Sustainable Development Goals and its Decade of Nutrition.

\section{Acknowledgements}

Financial support: This work was supported by the Conselho Nacional de Desenvolvimento Científico e Tecnológico (CNPq; grant number 443477/2014-0) and the Fundação de Amparo à Pesquisa do Estado de São Paulo (FAPESP; grant number 2015/14900-9). CNPq and FAPESP had no role in the design, analysis or writing of this article. Conflict of interest: The authors declare that there are no conflicts of interests. Authorship: All authors participated in the conception and drafting of the commentary. Ethics of buman subject participation: Not applicable.

\section{References}

1. Food and Agriculture Organization of the United Nations (2016) UN General Assembly proclaims Decade of Action on Nutrition. http://www.fao.org/news/story/en/item/ 408970/icode/ (accessed March 2017).

2. Global Panel on Agriculture and Food Systems for Nutrition (2016) Food Systems and Diets: Facing the Challenges of the 21st Century. London: Global Panel; available at http://glopan.org/sites/default/files/ForesightReport.pdf

3. Pan American Health Organization of the World Health Organization (2015) Ultra-Processed Food and Drink Products in Latin America: Trends, Impact on Obesity, Policy Implications. Washington, DC: PAHO; available at http://www.paho.org/hq/index.php?option=com_content\& view $=$ article $\& i d=11153 \% 3$ Aultra-processed-food-and-drinkproducts\&catid $=4999 \% 3$ Adocuments\&lang $=\mathrm{em}$

4. Monteiro CA (2009) Nutrition and health. The issue is not food, nor nutrients, so much as processing. Public Health Nutr 12, 729-731.

5. Food and Agriculture Organization of the United Nations (2015) Guidelines on the Collection of Information on Food Processing Through Food Consumption Surveys. Rome: FAO; available at http://www.fao.org/3/a-i4690e.pdf 
6. Food and Agriculture Organization of the United Nations \& Food Climate Research Network (2016) Plates, Pyramids, Planet. Developments in National Healthy and Sustainable Dietary Guidelines: A State of Play Assessment. Rome/Oxford: FAO/University of Oxford; available at http://www.fao.org/3/a-i5640e.pdf

7. Pan American Health Organization of the World Health Organization (2016) Nutrient Profile Model. Washington, DC: PAHO.

8. Ludwig D (2011) Technology, diet, and the burden of chronic disease. JAMA 305, 1352-1353.

9. Moodie R, Stuckler D, Monteiro CA et al. (2013) Profits and pandemics: prevention of harmful effects of tobacco, alcohol, and ultra-processed food and drink industries. Non-communicable Diseases Series 4. Lancet 381, 670-679.

10. Brazilian Ministry of Health (2014) Dietary Guidelines for the Brazilian Population. Brasilia: Ministry of Health; available at http://189.28.128.100/dab/docs/portaldab/ publicacoes/guia_alimentar_populacao_ingles.pdf

11. Monteiro CA, Cannon G, Moubarac J-C et al. (2015) Dietary guidelines to nourish humanity and the planet in the twenty-first century. A blueprint from Brazil. Public Health Nutr 18, 2311-2322.

12. de Souza R, Mente A, Maroleanu A et al. (2015) Intake of saturated and trans unsaturated fatty acids and risk of all cause mortality, cardiovascular disease, and type 2 diabetes: systematic review and meta-analysis of observational studies. BMJ 351, h3978.

13. World Health Organization (2003) Diet, Nutrition and the Prevention of Chronic Diseases. Report of a Joint WHO/ FAO Expert Consultation. WHO Technical Report Series no. 916. Geneva: WHO; available at http://www.who.int/ dietphysicalactivity/publications/trs916/en

14. World Cancer Research Fund/American Institute for Cancer Research (2007) Food, Nutrition, Physical Activity and the Prevention of Cancer: A Global Perspective. Washington, DC: AICR; available at http://www.aicr.org/ assets/docs/pdf/reports/Second_Expert_Report.pdf

15. US Department of Agriculture \& US Department of Health and Human Services (2010) Dietary Guidelines for Americans, 2010, 7th ed. Washington, DC: USDA/DHSS; available at http://www.cnpp.usda.gov/sites/default/files/ dietary_guidelines_for_americans/PolicyDoc.pdf

16. US Department of Agriculture \& US Department of Health and Human Services (2015) 2015-2020 Dietary Guidelines for Americans, 8th ed. Washington DC: USDA/DHSS; available at https://health.gov/dietaryguidelines/2015/ resources/2015-2020_Dietary_Guidelines.pdf.

17. Monteiro CA, Cannon G, Levy RB et al. (2012) The big issue for nutrition, disease, health, well-being. World Nutr 3, 527-569.

18. Stuckler D \& Nestle M (2012) Big food, food systems, and global health. PLoS Med 9, 6.

19. World Health Organization (2013) WHO Director-General addresses health promotion conference. http://www. who.int/dg/speeches/2013/health_promotion_20130610/ en/ (accessed March 2017).

20. Organisation for Economic Co-operation and Development (2002) Foreign Direct Investment for Development. Paris: OECD; http://www.oecd.org/investment/investment fordevelopment/foreigndirectinvestmentfordevelopmentmaxi misingbenefitsminimisingcosts.htm

21. Organisation for Economic Co-operation and Development (2016) Foreign Direct Investment (FDI) Statistics OECD Data, Analysis and Forecasts. Paris: OECD; http:// www.oecd.org/corporate/mne/statistics.htm

22. Wilkinson J (2004) The food processing industry, globalization, and developing countries. Electron J Agric Dev Econ 1, 184-201.
23. Hawkes C (2005) The role of foreign direct investment in the nutrition transition. Public Health Nutr 8, 357-365.

24. Monteiro CA \& Cannon G (2012) The impact of transnational 'Big Food' companies on the South: a view from Brazil. PLoS Med 9, e1001252.

25. Greer J \& Singh K (2000) A brief history of transnational corporations. Global Policy Forum. https://www.global policy.org/empire/47068-a-brief-history-of-transnationalcorporations.html (accessed March 2017).

26. European Food Information Council (2010) The Greatest Thing Since Sliced Bread? A Review of the Benefits of Processed Foods. Brussels: EUFIC; available at: http:// www.eufic.org/article/en/expid/benefits-processed-foodreview/

27. International Food Information Council (2010) Understanding our Food Information Communications Tool Kit. Washington, DC: IFIC Foundation; http://www.food insight.org/press-releases/international-food-informationcouncil-foundation-introduces-understanding-our-food

28. Eicher-Miller H, Fulgoni V \& Keast D (2012) Contributions of processed foods to dietary intake in the US from 20032008: a report of the Food and Nutrition Science Solutions Joint Task Force of the Academy of Nutrition and Dietetics, American Society for Nutrition, Institute of Food Technologists, and International Food Information Council. J Nutr 142, issue 11, 2065S-2072S.

29. Dwyer J, Fulgoni V, Clemens R et al. (2012) Is 'processed' a four-letter word? The role of processed foods in achieving dietary guidelines and nutrient recommendations. Adv Nutr 3, 536-548.

30. Weaver C, Dwyer J, Fulgoni V et al. (2014) Processed foods: contributions to nutrition. Scientific Statement from the American Society for Nutrition. Am J Clin Nutr 99, $1525-1542$

31. Eat Drink Politics, Simon M (2015) Nutrition Scientists on the Take from Big Food. Has the American Society for Nutrition Lost All Credibility? Oakland, CA: Eat Drink Politics; available at http://www.eatdrinkpolitics.com/wpcontent/uploads/ASNReportFinal.pdf

32. Monteiro CA, Levy RB, Claro RM et al. (2010) A new classification of foods based on the extent and purpose of their processing. Cad Saude Publica 26, 2039-2049.

33. Moubarac J-C, Parra D, Cannon G et al. (2014) Food classification systems based on food processing: significance and implications for policies and actions: a systematic literature review and assessment. Curr Obes Rep 3, 256-272.

34. Monteiro CA, Cannon G, Levy RB et al. (2015) Ultra-processing and a new classification of foods. In Introduction to the US Food System: Public Health, Environment, and Equity, pp. 338-339 [R Neff, editor]. San Francisco, CA: Jossey Bass/John Wiley.

35. Monteiro CA, Cannon G, Levy RB et al. (2016) NOVA. The star shines bright. World Nutr 7, 28-38.

36. Monteiro CA, Levy RB, Claro RM et al. (2011) Increasing consumption of ultra-processed foods and likely impact on human health: evidence from Brazil. Public Health Nutr 14, 5-13.

37. Sparrenberger K, Friedrich R, Schiffner M et al. (2015) Ultra-processed food consumption in children from a Basic Health Unit. J Pediatr (Rio J) 91, 535-542.

38. Martins AP, Levy RB, Claro RM et al. (2013) Increased contribution of ultra-processed food products in the Brazilian diet (1987-2009). Rev Saude Publica 47, 656-665.

39. Louzada ML, Martins AP, Canella DS et al. (2015) Ultra-processed foods and the nutritional dietary profile in Brazil. Rev Saude Publica 49, 38.

40. Barcelos GT, Rauber F \& Vitolo MR (2014) Processed and ultra-processed food products and nutrient intake in children. Rev Cienc Saude 7, 155-161. 
41. Bielemann R, Santos Motta J, Minten G et al. (2015) Consumption of ultra-processed foods and their impact on the diet of young adults. Rev Saude Publica 49, 28.

42. Louzada ML, Martins AP, Canella DS et al. (2015) Impact of ultra-processed foods on micronutrient content in the Brazilian diet. Rev Saude Publica 49, 45.

43. Canella DS, Levy RB, Martins AP et al. (2014) Ultraprocessed food products and obesity in Brazilian households (2008-2009). PLoS One 9, e92752.

44. Louzada ML, Baraldi LG, Martinez Steele E et al. (2015) Consumption of ultra-processed foods and obesity in Brazilian adolescents and adults. Prev Med 81, 9-15.

45. Tavares L, Fonseca S, Garcia Rosa L et al. (2012) Relationship between ultra-processed foods and metabolic syndrome in adolescents from a Brazilian family doctor program. Public Health Nutr 15, 82-87.

46. Rauber F, Campagnolo P, Hoffman D et al. (2015) Consumption of ultra-processed food products and its effects on children's lipid profiles: a longitudinal study. Nutr Metab Cardiovasc Dis 25, 116-122.

47. Moubarac J-C, Claro RM, Baraldi LG et al. (2013) International differences in cost and consumption of readyto-consume food and drink products: United Kingdom and Brazil, 2008-2009. Glob Public Health 8, 845-856.

48. Leite FH, Oliveira MA, Cremm EC et al. (2012) Availability of processed foods in the perimeter of public schools in urban areas. I Pediatr (Rio J) 88, 328-334.

49. Costa JC, Claro RM, Martins AP et al. (2013) Food purchasing sites. Repercussions for healthy eating. Appetite 70, 99-103.

50. Vedovato GM, Trude AC, Kharmats AY et al. (2015) Degree of food processing of household acquisition patterns in a Brazilian urban area is related to food buying preferences and perceived food environment. Appetite 87, 296-302.

51. Mallarino C, Gomez L, Gonzalez-Zapata L et al. (2013) Advertising of ultra-processed foods and beverages: children as a vulnerable population. Rev Saude Publica 47 , 1006-1010.

52. Franco P, Rosa G, Luiz R et al. (2015) Assessment of the quality of hypoenergetic diet in overweight women. Int J Cardiovasc Sci 28, 244-250.

53. Martinez Steele E, Baraldi LG, Louzada ML et al. (2015) Ultra-processed foods and added sugars in the US diet: evidence from a nationally representative crosssectional study. BMJ Open 5, e009892.

54. Martinez Steele E, Popkin B, Swinburn B et al. (2017) The share of ultra-processed foods and the overall nutritional quality of diets in the US: evidence from a nationally representative cross-sectional study. Popul Health Metr 15, 6 .

55. Martinez Steele E \& Monteiro CA (2017) Association between dietary share of ultra-processed foods and urinary concentrations of phytoestrogens in the US population. Nutrients $\mathbf{9}, 3$.

56. Poti JM, Mendez MA, Ng SW et al. (2015) Is the degree of food processing and convenience linked with the nutritional quality of foods purchased by US households? Am J Clin Nutr 101, 1251-1262.

57. Poti JM, Mendez MA \& Ng SW (2016) Highly processed and ready-to-eat packaged food and beverage purchases differ by race/ethnicity among US households. J Nutr $\mathbf{1 4 6}$, 1722-1730

58. Moubarac J-C, Batal M, Martins AP et al. (2014) Processed and ultra-processed food products: consumption trends in Canada from 1938 to 2011. Can J Diet Pract Res 75, 15-21.

59. Moubarac J-C, Martins AP, Claro RM et al. (2013) Consumption of ultra-processed foods and likely impact on human health. Evidence from Canada. Public Health Nutr 16, 2240-2248.
60. Moubarac J-C, Batal M, Louzada ML et al. (2017) Consumption of ultra-processed foods predicts diet quality in Canada. Appetite 108, 512-520.

61. Moreira P, Baraldi LG, Moubarac J-C et al. (2015) Comparing different policy scenarios to reduce the consumption of ultra-processed foods in UK: impact on cardiovascular disease mortality using a modelling approach. PLoS One 10, e0118353.

62. O'Halloran SA, Grimes CA, Lacy KE et al. (2016) Dietary sources and sodium intake in a sample of Australian preschool children. BMJ Open 6, e008698.

63. Venn D, Banwell C \& Dixon J (2016) Australia's evolving food practices: a risky mix of continuity and change. Public Health Nutr (Epublication ahead of print version).

64. Harray AJ, Boushey CJ, Pollard CM et al. (2015) A novel dietary assessment method to measure a healthy and sustainable diet using the mobile food record: protocol and methodology. Nutrients 7, 5375-5395.

65. Crovetto M, Uauy R, Martins AP et al. (2014) Household availability of ready-to-consume food and drink products in Chile: impact on nutritional quality of the diet. Rev Med Chile 142, 850-858.

66. Cediel G, Reyes M, Louzada MLC et al. (2017) Contribution of ultra-processed foods to total energy and added sugars in Chilean diet. Public Health Nutr (under review).

67. Marrón-Ponce JA, Sánchez-Pimienta T, Louzada ML et al. (2017) Energy contribution of ultra-processed foods and sociodemographic determinants in the Mexican population. Public Health Nutr (under review).

68. Solberg SL, Terragni L \& Granheim SI (2016) Ultraprocessed food purchases in Norway: a quantitative study on a representative sample of food retailers. Public Health Nutr 19, 1990-2001.

69. Luiten C, Steenhuis I, Eyles H et al. (2016) Ultra-processed foods have the worst nutrient profile, yet they are the most available packaged products in a sample of New Zealand supermarkets. Public Health Nutr 19, 530-538.

70. Juul F \& Hemmingsson E (2015) Trends in consumption of ultra-processed foods and obesity in Sweden between 1960 and 2010. Public Health Nutr 18, 3096-3107.

71. Mendonça R, Pimenta A, Gea A et al. (2016) Ultra-processed foods consumption and risk of overweight/obesity: the SUN cohort study. Am J Clin Nutr 104, 1433-1440.

72. Mendonça R, Lopes A, Pimenta A et al. (2016) Ultraprocessed food consumption and the incidence of hypertension in a Mediterranean cohort: the Seguimiento Universidad de Navarra Project. Am J Hypertens (Epublication ahead of print version).

73. Monteiro CA, Moubarac J-C, Cannon G et al. (2013) Ultraprocessed products are becoming dominant in the global food system. Obes Rev 14, Suppl. 2, 21-28.

74. Baker P, Kay A \& Walls H (2014) Trade and investment liberalization and Asia's noncommunicable disease epidemic: a synthesis of data and existing literature. Global Health 10, 66.

75. World Health Organization (2017) The Influence of Ultraprocessed Foods on the Dietary Content of Free Sugars in the US, Canada, Brazil and Colombia. Geneva: WHO (In the Press).

76. Vandevijvere S, Monteiro CA, Krebs-Smith S et al. (2013) Monitoring and benchmarking population diet quality globally: a step-wise approach. Obes Rev 14, Suppl. 1, 135-149.

77. Ministerio de Salud (2016) Guía Alimentaria para la Población Uruguaya. http://msp.gub.uy/sites/default/files/ archivos_adjuntos/MS_guia_web.pdf (acessed March 2017).

78. Prentice A \& Jebb S (2003) Fast foods, energy density and obesity: a possible mechanistic link. Obes Rev $\mathbf{4}$, 187-194. 
79. Fardet A (2016) Minimally processed foods are more satiating and less hyperglycemic than ultra-processed foods: a preliminary study with 98 ready-to-eat foods. Food Funct 7, 2338-2346.

80. Brownell K \& Gold M (2012) Food and Addiction. A Comprehensive Handbook. Oxford: Oxford University Press.

81. Gearhardt A (2015) The science behind food and addiction and the potential effect on the food system. In Introduction to the US Food System: Public Health, Environment, and Equity, pp. 405-406 [R Neff, editor]. San Francisco, CA: Jossey Bass/John Wiley.

82. La Fontaine HA, Crowe TC, Swinburn BA et al. (2004) Two important exceptions to the relationship between energy density and fat content: foods with reduced-fat claims and high-fat vegetable based dishes. Public Health Nutr 7 , 563-568.

83. Scrinis G (2016) Reformulation, fortification and functionalization: Big Food corporations' nutritional engineering and marketing strategies. J Peasant Stud 43, 17-37.

84. Chandon P \& Wansink B (2012) Does food marketing need to make us fat? A review and solutions. Nutr Rev 70, 571-593.

85. Taylor A \& Jacobson M (2016) Carbonating the World: The Marketing and Health Impact of Sugar Drinks in Low- and Middle-Income Countries. Washington, DC: Center for Science in the Public Interest.

86. Cairns G, Angus K \& Hastings G (2009) The Extent, Nature and Effects of Food Promotion to Children: A Review of the Evidence to December, 2008. Geneva: WHO.

87. Global Burden of Disease Risk Factors Collaborators (2016) Global, regional, and national comparative risk assessment of 79 behavioural, environmental and occupational and metabolic risks or clusters of risks, 1990-2015: a systematic analysis for the Global Burden of Disease Study 2015. Lancet 388, 1659-1724.

88. Wrangham R (2009) Catching Fire: How Cooking Made Us Human. New York: Basic Books; available at https:// archive.org/stream/pdfy-DDoNCJJ_Wt0qOH7e/Catching\% 20Fire\%20[How\%20Cooking\%20Made\%20Us\%20Human]_ djvu.txt

89. Garner D (2009) Why are humans different from all other apes? It's the cooking, stupid. The New York Times, 26 May. http://www.nytimes.com/2009/05/27/books/27 garn.html (accessed March 2017).

90. Pollan M (2013) Cooked. A Natural History of Transformation. New York: The Penguin Press; available at https://www.amazon.co.uk/Cooked-Natural-TransformationMichael-Pollan/dp/0141975628

91. Schlosser E (2000) Fast Food Nation. The Dark Side of the All-American Meal. New York: Houghton Mifflin; available at https://www.nytimes.com/books/first/s/ schlosser-fast.html

92. Hawkes C (2006) Uneven dietary development: linking the policies and processes of globalization with the nutrition transition, obesity and diet-related chronic diseases. Global Health 2, 4.

93. Monteiro CA, Gomes F \& Cannon G (2010) The snack attack. Am J Public Health 100, 975-981.

94. Story M \& French S (2004) Food advertising and marketing directed at children and adolescents in the US. Int J Behav Nutr Phys Act 1, 3.

95. World Health Organization (2014) Protecting children from the harmful effects of food and drink marketing. http://www.who.int/features/2014/uk-food-drink-marketing/ en/ (accessed March 2017).

96. Rockefeller Foundation (2013) Unhealthy Developing World Food Markets. New York: Rockefeller Foundation; available at https://www.rockefellerfoundation.org/app/ uploads/Unhealthy-Developing-World-Food-Markets.pdf
97. International Food Policy Research Institute (2016) Global Nutrition Report 2016. From Promise to Impact: Ending Malnutrition by 2030. Washington, DC: IFPRI.

98. Black E (2016) Globalization of the Food Industry: Transnational Corporations, the Spread of Processed Food, and their Implications for Food Security and Nutrition. Independent Study Project (ISP) Collection no. 2353. Brattleboro, VT: SIT Graduate Institute; available at http://digitalcollections.sit.edu/isp_collection/2353

99. Brown L (2013) Good and cheap. Eat well on $\$ 4$ a day. https://www.kickstarter.com/projects/490865454/goodand-cheap (accessed March 2017).

100. Monroe J (2014) A Girl Called Jack. 100 Delicious Budget Recipes. London: Penguin.

101. Wiggins S, Keats S, Han E et al. (2015) The Rising Cost of a Healthy Diet. Changing Relative Prices of Foods in Highincome and Emerging Economies. London: Overseas Development Institute.

102. Claro RM, Maia EG, Costa BVL et al. (2016) Preço dos alimentos no Brasil: prefira preparações culinárias a alimentos ultraprocessados (Food prices in Brazil: prefer cooking to ultra-processed foods). Cad Saude Publica 32, e00104715.

103. American Diabetes Association (2013) Economic costs of diabetes in the US in 2012. Diabetes Care 36, 1033-1046.

104. Institute of Food Technologists (2007) Food packaging and its environmental impact. Food Technol April issue, 46-50; available at http://www.ift.org/knowledge-center/readift-publications/science-reports/scientific-status-summaries/ editorial/food-packaging-and-its-environmental-impact.aspx

105. Natural Resources Defense Council (2007) Food Miles. How Far Your Food Travels has Serious Consequences for Your Health and the Climate. New York: NRDC; available at https://food-hub.org/files/resources/Food\%20Miles.pdf

106. Union of Concerned Scientists (2016) Hidden costs of industrial agriculture. http://www.ucsusa.org/food_and_ agriculture/our-failing-food-system/industrial-agriculture/ hidden-costs-of-industrial.html\#.V_2BRfkrLIU (accessed January 2017).

107. Spanne A (2014) Fighting climate change in Brazil isn't just about the Amazon. The Daily Climate, 10 November. http://www.dailyclimate.org/tdc-newsroom/2014/11/brazilmeat-cerrado-deforestation (accessed March 2017).

108. Rockstrom J, Steffen W, Noone K et al. (2009) Planetary boundaries: exploring the safe operating space for humanity. Ecol Soc 14, 32.

109. Crutzen P \& Schwägerl C (2011) Living in the Anthropocene: towards a new global ethos. http://e360.yale.edu/ feature/living_in_the_anthropocene_toward_a_new_global_ ethos/2363/ (accessed March 2017).

110. Carrington D (2016) The Anthropocene epoch: scientists declare dawn of human-influenced age. The Guardian, 29 August. https://www.theguardian.com/environment/2016/ aug/29/declare-anthropocene-epoch-experts-urge-geologicalcongress-human-impact-earth (accessed March 2017).

\section{Appendix}

\section{The NOVA classification}

The NOVA classification, outlined above, groups foods according to the nature, extent and purpose of the industrial processing they undergo. Food processing as identified by NOVA involves physical, biological and chemical processes used after foods are separated from nature, and before being consumed or prepared as dishes and meals. Methods used in the culinary preparation of 
food at home or in restaurant kitchens are not industrial, by definition, and so are not taken into account by NOVA, which classifies all foods, including culinary ingredients and other food products, into the following four groups. This Appendix lists the main items in the four groups.

Group 1. Unprocessed or minimally processed foods This first NOVA group of unprocessed and minimally processed foods includes fresh, squeezed, chilled, frozen or dried fruits and leafy and root vegetables; grains such as brown, parboiled or white rice, corn cob or kernel, wheat berry or grain; legumes such as beans of all types, lentils, chickpeas; starchy roots and tubers such as potatoes and cassava, in bulk or packaged; fungi such as fresh or dried mushrooms; meat, poultry, fish and seafood, whole or in the form of steaks, fillets and other cuts, or chilled or frozen without added salt or oil; eggs; milk, pasteurized or powdered; fresh or pasteurized fruit or vegetable juices without added sugar, sweeteners or flavours; grits, flakes or flour made from corn, wheat, oats or cassava; pasta, couscous and polenta made with flours, flakes or grits and water without added salt or oil; tree and ground nuts and other oilseeds without added salt or sugar; spices such as pepper, cloves and cinnamon and herbs such as thyme and mint, fresh or dried; plain yoghurt with no added sugar or artificial sweeteners; tea and coffee with no added sugar; drinking-water.

\section{Group 2. Processed culinary ingredients}

This second NOVA group of processed culinary ingredients includes vegetable oils crushed from various seeds or nuts, or fruits such as olives; butter and lard obtained from milk and pork; starches extracted from corn and other plants; sugar and molasses obtained from cane or beet; honey extracted from combs and syrup from maple trees; and salt mined or from seawater.

\section{Group 3. Processed foods}

This third NOVA group of processed foods includes canned or bottled vegetables, fruits and legumes; salted or sugared nuts and seeds; salted, pickled, cured or smoked meats and other animal foods; canned fish; fruits in syrup; cheeses; and unpackaged freshly made breads.

\section{Group 4. Ultra-processed foods}

This fourth NOVA group of ultra-processed food products includes carbonated drinks; sweet or savoury packaged snacks; ice cream, chocolate, candies (confectionery); mass-produced packaged breads, buns, cookies (biscuits), pastries, cakes and cake mixes; breakfast 'cereals', 'cereal' and 'energy' bars; margarines and spreads; processed cheese; 'energy' drinks; sugared milk drinks, sugared 'fruit' yoghurts and 'fruit' drinks; sugared cocoa drinks; meat and chicken extracts and 'instant' sauces; infant formulas, follow-on milks and other baby products (which may include expensive ingredients); 'health' and 'slimming' products such as powdered or 'fortified' meal and dish substitutes; and many ready-to-heat products including pre-prepared pies and pasta and pizza dishes; poultry and fish 'nuggets' and 'sticks'; sausages, burgers, hot dogs and other reconstituted meat products; and powdered and packaged 'instant' soups, noodles and desserts. 